\title{
Práticas de enfermagem às mulheres que vivenciaram aborto: revisão integrativa
}

RESUMO | Objetivo: caracterizar como ocorrem e quais os efeitos das ações de Enfermagem na saúde de mulheres no momento do aborto. Método: Revisão integrativa, realizada nas bases de dados SciELO, LILACS e BDENF, a partir dos descritores: saúde da mulher, aborto e cuidados de Enfermagem. Resultados: Dezenove artigos foram selecionados, publicados no período de 2015 a 2020. Percebeu-se, na maioria das produções, prática fragmentada de profissionais de Enfermagem às mulheres em situação de abortamento, seja nos aspectos relacionais, de manejo da dor e da educação em saúde sobre o que fazer pós-alta. Embora conhecimento de protocolos e da humanização, o cuidado ainda é afetado por crenças e valores desses profissionais. Conclusão: Conclui-se que o cuidado de Enfermagem voltado ao aborto ainda visa problema e julgamentos, e exige, dentre outros aspectos, permanente qualificação profissional para que seja centrado na pessoa, supere os maus-tratos e garanta bem estar e segurança em futuras gestações.

Palavras-chaves: Aborto; Saúde da mulher; Cuidados de Enfermagem.

\begin{abstract}
Objectives: to characterize how they occur and what are the effects of nursing actions on women's health at the time of abortion. Methods: It is an integrative review. The search took place in the SciELO, LILACS and BDENF databases, based on the keywords: women's health, abortion and nursing care. Results: Nineteen articles were selected, published from 2015 to 2020. It was noticed, in most productions, a fragmented practice of nursing professionals to women in abortion situations, whether in the relational, pain management and health education aspects of what to do after discharge. Although knowledge of protocols and humanization, care is still affected by the beliefs and values of these professionals. Conclusions: It is concluded that nursing care aimed at abortion still aims at problems and judgments, and requires, among other aspects, permanent professional qualification so that it is centered on the person, overcomes the abuse and ensures well-being and safety in future pregnancies Keywords: Abortion; Women's health; Nursing care.
\end{abstract}

RESUMEN | Objetivos: caracterizar cómo ocurren y cuáles son los efectos de las acciones de enfermería en la salud de las mujeres en el momento del aborto. Método: Es una revisión integradora. La búsqueda se realizó en las bases de datos SciELO, LILACS y BDENF, en base a las palabras clave: salud de la mujer, aborto y cuidados de enfermería. Resultados: Se notó, en la mayoría de las producciones, una práctica fragmentada de los profesionales de enfermería a las mujeres en situaciones de aborto, ya sea en los aspectos relacionales, manejo del dolor y educación para la salud de qué hacer después del alta. Aunque el conocimiento de los protocolos y la humanización, el cuidado sigue estando afectado por las creencias y valores de estos profesionales. Conclusión: Se concluye que el cuidado de enfermería orientado al aborto aún apunta a problemas y juicios, y requiere, entre otros aspectos, la calificación profesional permanente para que se centre en la persona, supere el abuso y garantice el bienestar y la seguridad en futuros embarazos.

Palabras claves: Aborto; Salud de la Mujer; Atención de Enfermería.

\section{Thaís Edna Rodrigues Santos}

Discente de enfermagem, Universidade Estadual de Santa Cruz - UESC. Ilhéus, BA, Brasil.

ORCID: 0000-0002-1207-0685

\section{Dejeane de Oliveira Silva}

Doutora. Professora do Curso de Enfermagem, Universidade Estadual de Santa Cruz, Ilhéus, Bahia, Brasil.

ORCID: 0000-0002-1798-3758

\section{Rozemere Cardoso de Souza}

Doutora. Professora do Curso de Enfermagem, Universidade Estadual de Santa Cruz, BA, Brasil.

ORCID: 0000-0003-2705-1556

Recebido em: 29/09/2020

Aprovado em: 27/11/2020

\section{Thiago Nogueira Silva}

Mestre, Coordenador de Vigilância em Saúde, Conceição da Feira, BA, Brasil. ORCID: 0000-0002-8666-8698

\section{INTRODUÇÃO}

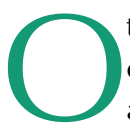
termo aborto define a descontinuação da gravidez antes da $22^{\mathrm{a}}$ semana de gestação, sendo precoce aquele ocorrido até a $13^{\mathrm{a}}$ semana, e tardio, entre a $13^{\mathrm{a}}$ e $22^{\mathrm{a}}$ semanas. Trata-se de um dos maiores problemas de saúde pública no país, evidenciado por ocupar o $4^{\circ}$ lugar entre as causas de morte maternas, com mais de um miIhão de ocorrências induzidas por ano ${ }^{(1,2)}$.

Dados da Pesquisa Nacional de Aborto (PNA) mostram que o aborto é comum nas mulheres brasileiras de todas as idades da vida reprodutiva e de diferentes condições sociodemográficas, das 2.002 mulheres entrevistadas em 2016 com idades entre 18 e 39 anos e alfabetizadas 251 (13\%) já fizeram ao menos um aborto, aproximadamente 1 a cada 5 muIheres aos 40 anos já fez aborto, sendo que a frequência dos abortos é maior em mulheres mais jovens com 29\% entre 12 a 19 anos, $28 \%$ entre 20 a 24 anos e $13 \%$ a partir de 25 anos(2). Sob a perspectiva da saúde pública e dos direitos humanos, questões como criminalização e déficit de acesso à saúde sexual e reprodutiva também implicam em consequências biopsicossociais e risco à vida das mulheres que recorrem às práticas clandestinas e/ou inseguras do aborto ${ }^{(3-4)}$. 
Estudos apontam a necessidade de melhorias do acolhimento às mulheres que vivenciaram o aborto ${ }^{(5-6)}$, pois em muitos lugares os profissionais não acoIhem ou orientam essas mulheres sem julgamento, ferindo princípios da integralidade da atenção e da Norma técnica do Ministério da Saúde do Brasil ${ }^{(7)}$.

Por conta disso e das evidências de alta ocorrência de abortos inseguros entre as mulheres ${ }^{(6)}$, o tema é alvo crescente de estudos na área da Enfermagem ${ }^{(8)}$, profissão diretamente implicada na assistência aos casos de abortamento, seja espontâneo, seja provocado, sendo importante a informação para o desenvolvimento de políticas mais efetivas de assistência e do direito à vida de mulheres nessa condição ${ }^{(4)}$. Importante destacar também a intersecção de variáveis que potencializam vulnerabilidades das muIheres que pertencem às classes sociais mais baixas, maioria negras e com baixa escolaridade.

Este estudo questionou sobre o que diz a literatura acerca da produção do cuidado de Enfermagem às mulheres com história de aborto. Assim, teve por objetivo caracterizar, através da literatura, ações de Enfermagem e suas implicações sociais, na saúde de mulheres em situação de aborto.

\section{MÉTODO}

Revisão integrativa da literatura, que é relevante para produção de síntese e incorporação da aplicabilidade de resultados de estudos significativos na prática, segue 6 fases no seu processo de elaboração: elaboração da pergunta norteadora; busca ou amostragem na literatura; coleta de dados; análise crítica dos estudos incluídos; discussão dos resultados; e apresentação da revisão integrativa. (9). A questão norteadora foi: como se dá a prática de enfermagem às mulheres que vivenciaram o aborto e como isso afeta a sua saúde?

A pesquisa foi realizada nas seguintes bases de dados do portal da Biblioteca
Por conta disso e das evidências de alta ocorrência de abortos inseguros entre as mulheres, o tema é alvo crescente de estudos na área da Enfermagem, profissão diretamente implicada na assistência aos casos de abortamento

Virtual em Saúde (BVS): SciELO, LILACS e BDENF, nos meses de setembro de 2019 e fevereiro de 2020, a partir dos descritores: Aborto, Saúde da mulher e Cuidados de enfermagem. Foram selecionados 19 artigos que atenderam aos seguintes critérios de inclusão: estar publicado na forma de artigos, em português, inglês ou espanhol, no período de 2015 à 2018; estar disponível na rede midiática na íntegra; apresentar conteúdos relevantes ao tema de pesquisa. Foram excluídos os artigos relacionados ao aborto que não faziam referência aos cuidados de enfermagem (Figura 1).

Fez-se análise da produção selecionada, a partir de leituras de todos os artigos na íntegra, produção de fichamentos e sínteses, e de quadro contendo: autores, ano, país, objetivos, tipo de pesquisa e principais resultados.

\section{RESULTADOS}

Dos 19 artigos investigados, 18 estavam disponíveis na língua portuguesa, sendo a maioria publicada em periódicos da Enfermagem de veiculação internacional. Nos últimos 5 anos, o ano de maior produção foi 2018, até a data da coleta de dados. Os autores, em sua maioria, eram enfermeiros vinculados às instituições de ensino superior e/ou aos hospitais universitários, tendo por país de afiliação o Brasil.

A análise dos dados permitiu a elaboração de uma síntese desta revisão integrativa, apresentada no Quadro 1.

Grande parte dos estudos foi reali-
Figura 1 - Fluxograma descritor das etapas de seleção dos materiais deste estudo.

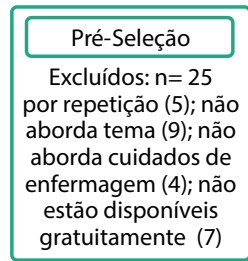

\begin{tabular}{|c|}
\hline Elegibilidade \\
Selecionados: $\mathrm{n}=27$ \\
Após acesso ao texto \\
na íntegra e leitura, \\
foram excluídos: \\
$\mathrm{n}=8$
\end{tabular}

Incluídos

Incluídos: $\mathrm{n}=19$ 
Quadro 1 - Síntese dos estudos incluídos na revisão integrativa. SciELO, LILACS, BVS, 2015 a 2020.

\begin{tabular}{|l|c|}
\hline Autores/Ano/ País & \multicolumn{1}{|c|}{ Tema do estudo } \\
\hline $\begin{array}{l}\text { Melchiors, Madi, Maggi, } \\
\text { Rosa, Sossela/ 2015/ } \\
\text { Brasil'10 }\end{array}$ & $\begin{array}{l}\text { Experiências emocionais das pacientes atendidas } \\
\text { em um serviço de referência para o atendimento de } \\
\text { vítimas de violência sexual e mulheres em situação } \\
\text { de aborto previsto em lei. }\end{array}$ \\
\hline $\begin{array}{l}\text { Camarneiro, Maciel, } \\
\text { Silveira/ 2015/Portugal11 }\end{array}$ & $\begin{array}{c}\text { Vivência da Interrupção da Gravidez em mulheres } \\
\text { primigestas de um serviço de Obstetrícia e Ginecolo- } \\
\text { gia de um hospital. }\end{array}$
\end{tabular}

Silveira/ 2015/Portugal ${ }^{11}$

\begin{tabular}{l|l} 
Silva, Trevisan, Lorenzini, \\
$\begin{array}{l}\text { Pruss, et al// 2015/Bra- } \\
\text { sil }^{12}\end{array}$
\end{tabular} $\begin{gathered}\begin{array}{c}\text { Percepção de profissionais de enfermagem em } \\
\text { relação à atenção à mulher em processo de aborta- } \\
\text { mento induzido. }\end{array}\end{gathered}$

Strefling, Lunardi, Kerber, Soares, Ribeiro/ 2015/Brasil ${ }^{13}$

Sell et al./ 2015/ Brasil'

Contribuição das pesquisas desenvolvidas sobre 0 que motiva as mulheres a induzirem o aborto e 0 significado dessa experiência em suas vidas.

Gestão e realização do cuidado às mulheres hospitalizadas por abortamento sob a perspectiva dos profissionais de enfermagem.

\begin{tabular}{|l|c|} 
& significado dessa experiência em suas vidas. \\
\hline $\begin{array}{l}\text { Paço, Deodato/ 2015/ } \\
\text { Portugal15. }\end{array}$ & $\begin{array}{c}\text { Objeção de consciência na prática da enfermagem: } \\
\text { fundamentação ética e legal, para a tomada de } \\
\text { decisão. }\end{array}$
\end{tabular}

Silveira, McCallum, Menezes/ 2016/ Brasil'16.

Experiências de abortos provocados de pessoas de estratos sociais médios realizados em clínicas privadas no nordeste brasileiro.

Milanez, Oliveira, Barroso, Martinelli, Espoti, Neto/ 2016/ Brasil ${ }^{17}$.

McCallum, Menezes, Reis/ 2016/ Brasil ${ }^{18}$.

Pitilin, Banazeski, Bedin, Gaparin/ 2016/Brasil ${ }^{19}$.

Rodrigues et. al., Silval 2017/ Brasili20.

Madeiro, Rufino/ 2017/ Brasil22.
Processos de simbolização da atenção hospitalar e suas implicações às experiências de mulheres.

Assistência de enfermagem em situações de aborto induzido/provocado.

Aplicação do Protocolo de Enfermagem na Assistência às Mulheres em processo de abortamento.

Aspectos da gravidez indesejada e da tentativa de aborto revelados numa avaliação da assistência pré-natal.

istórias de violência institucional na assistência ao aborto provocado, sob a ótica das mulheres assistidas em hospital.

\section{Principais resultados}

Evidências de potencialidades do atendimento e relação favorável das pacientes com a equipe cuidadora; eventuais fragilidades nos protocolos da equipe interdisciplinar; especial atenção ao contexto em que a paciente ingressa no serviço, sob o impacto da violência e/ou do diagnóstico.

Ocorre o desfazer do sonho que resulta da privação súbita da gravidez e da maternidade desejada, descrito por três temas centrais: vivência de sentimentos negativos, elaboração interior e desejo de garantia da maternidade.

Emergiram duas categorias de análise: o papel da enfermagem no atendimento à mulher em processo de abortamento induzido; e não estar capacitada para atender à mulher em processo de abortamento induzido.

Comportamento discriminatório e pouca interação dos profissionais com a mulher, focado em aspectos clínicos. Outro, marcado por apoio emocional e provisão de ambiente terapêutico privativo, independentemente da etiologia do aborto.

Evidência de aspectos para melhoria do cuidado de mulheres em situação de aborto induzido: necessidade de atenção ao estado emocional das mesmas, o respeito ao silêncio quanto à indução, e a falta de ações preventivas que antecedam 0 aborto. Importância das pesquisas para fundamentar a prática da enfermagem.

Descreve direito dos profissionais em recusar a fazer qualquer ato contrário aos seus preceitos morais, éticos, religiosos, porém, ressalta, em casos de risco de vida, o atendimento não pode ser negado.

Aborto em clínica privada não é garantia de atendimento humanizado e seguro. São descritas falhas nas práticas, como a falta de informações sobre os medicamentos, até outras com abusos graves, como procedimentos realizados sem anestesia.

Evidências da tentativa de aborto inseguro em consequência da gravidez indesejada. Reveladas vulnerabilidades das mulheres, relacionada ao conhecimento popular sobre riscos do aborto para o bebê.

Argumentam que a forma pela qual a instituição estrutura a atenção ao aborto e os processos de simbolização a ela imbricados afetam profundamente as experiências das mulheres.

Percebeu-se que a atuação do enfermeiro é tecnicista, discriminatória, julgatória e burocrática, contradizendo diretrizes do código de ética da profissão.

Descrevem o uso de protocolo de cuidado, dividido em três etapas: acolhimento, assistência de enfermagem e cuidado ambulatorial.

Julgamento moral, ameaças de denúncia à polícia, negligência

no controle da dor, longa espera pela curetagem uterina e internação conjunta com puérperas foram os principais tipos de violência institucional narrados. 


\begin{tabular}{|c|c|c|}
\hline $\begin{array}{l}\text { Santos, Brito/ 2017/ } \\
\text { Brasil'32. }^{23}\end{array}$ & $\begin{array}{l}\text { Sentimentos experienciados por mulheres no proces- } \\
\text { so de concretização da prática abortiva. }\end{array}$ & $\begin{array}{l}\text { Conflitos entre valores morais, resultando em sentimentos de } \\
\text { transgressão da moralidade, desencadeando tristeza, medo da } \\
\text { morte e do nascimento de filho deficiente. }\end{array}$ \\
\hline $\begin{array}{l}\text { Fernandes, Xavier, São } \\
\text { Bento, Rodrigues/ 2017/ } \\
\text { Brasil24. }\end{array}$ & $\begin{array}{l}\text { Vivências das mulheres de fetos com anencefalia e } \\
\text { identificar os fatores determinantes para a escolha } \\
\text { de interromper ou não interromper a gestação }\end{array}$ & $\begin{array}{l}\text { Relatos de vivências intensas em relação ao cuidado e à proble- } \\
\text { mática da interrupção da gestação. Para alívio do desconforto e } \\
\text { dor, recomendam-se cuidar do ambiente, deixando as mulheres } \\
\text { em situação de pós-aborto, em quartos e/ ou enfermarias separa- } \\
\text { das daquelas com mães e seus bebês. }\end{array}$ \\
\hline $\begin{array}{l}\text { Martins, Almeida et al./ } \\
\text { 2017/ Brasil25. }\end{array}$ & $\begin{array}{l}\text { Evolução da mortalidade materna por aborto em } \\
\text { Minas Gerais, Brasil, no período de } 2000 \text { a 2011, sob } \\
\text { o enfoque das causas múltiplas de morte. }\end{array}$ & $\begin{array}{l}\text { Problemas oriundos da ilegalidade da prática de abortos favore- } \\
\text { cem o aparecimento de causas que mascaram mortes maternas } \\
\text { e notificação. }\end{array}$ \\
\hline $\begin{array}{l}\text { Ayres, Xavier, Silva, } \\
\text { Martins, São Bento; } \\
\text { Silva/ 2018/ Brasil26. }\end{array}$ & $\begin{array}{l}\text { Opinião de enfermeiros do sexo masculino quanto } \\
\text { ao aborto provocado }\end{array}$ & $\begin{array}{l}\text { Existe invisibilidade masculina quando se trata de gestação inde- } \\
\text { sejada, onde a figura feminina é sempre colocada como culpada, } \\
\text { imprudente ou responsável. }\end{array}$ \\
\hline $\begin{array}{l}\text { Patrício, Gregório, } \\
\text { Pereira, Costa/ 2019/ } \\
\text { Brasil'7. }\end{array}$ & $\begin{array}{l}\text { Dilemas maternos sobre o diagnóstico de malforma- } \\
\text { ção fetal incompatível com a vida }\end{array}$ & $\begin{array}{l}\text { Experiências pautadas por sofrimento e emoções. A escolha da } \\
\text { interrupção alicerçada a fatores pessoais e famílias, como infor- } \\
\text { mação da patologia e religião. Importante promover comunica- } \\
\text { ção transparente entre mulher, família e equipe interdisciplinar } \\
\text { no transcorrer da gestação e parto. }\end{array}$ \\
\hline $\begin{array}{l}\text { Moreira, Viera, } \\
\text { Cavalcanti, Silva/2020/ } \\
\text { Brasil' }{ }^{28} \text {. }\end{array}$ & $\begin{array}{l}\text { Manifestações de violência institucional na atenção } \\
\text { em saúde às mulheres em situação de violência } \\
\text { sexual. }\end{array}$ & $\begin{array}{l}\text { Não reconhecimento da violência sexual como objeto de } \\
\text { intervenção no setor saúde, e o acolhimento à mulher marcado } \\
\text { por omissões, falta de privacidade, atitudes discriminatórias. Con- } \\
\text { dições estruturais e escassez de medicamentos e insumos são } \\
\text { limitantes para o atendimento. } 0 \text { aborto legal envolveu conflitos } \\
\text { culturais, gerenciais e institucionais, implicando na violação de } \\
\text { direitos. }\end{array}$ \\
\hline
\end{tabular}

zada na perspectiva de investigar temas relacionados à percepção e vivências de mulheres frente à situação de abortamento, com destaque à violência institucional sofrida por essas. Nota-se a realização de estudos na perspectiva de analisar o cuidado oferecido por profissionais, bem como a sua percepção diante da produção do cuidado às mulheres nessa condição. Quanto ao método, os estudos evidenciaram predominância de escolha para a abordagem qualitativa. Ao todo, foram 13 pesquisas qualitativas $^{(10-13,15-17,21-24,26-28)}, 2$ de abordagem quantiqualitativa ${ }^{(17,18)}, 2$ estudos de revisão ${ }^{(14,19)}, 1$ pesquisa ecológica ${ }^{(25)} \mathrm{e}$ 1 relato de experiência ${ }^{(20)}$.

\section{DISCUSSÃO}

Os dados revelaram que na maioria das produções, a assistência às mulheres mostrou-se fragmentada, sem empatia, acolhimento ou orientações sobre os procedimentos e o que fazer após a alta dos serviços de saúde. O manejo da dor, após o abortamento, inclusive, é inexistente ou ocorre de forma incorreta ${ }^{(22)}$. Como consequência, podem ocorrer traumas, sentimentos de tristeza, angústias e desamparo $^{(29)}$. Apenas em um artigo, os profissionais de enfermagem foram vistos como pessoal de apoio a essas muIheres, onde acolheram, orientaram e deram todo o suporte necessário ${ }^{(16)}$. Tais aspectos reforçam o cuidado que gera adoecimentos e que não se alinha com a política de humanização em situação de abortamento.

Nesse sentido, apesar dos Enfermeiros conhecerem os protocolos para a assistência ao aborto, e terem entendimento sobre o cuidado singularizado a cada mulher, as suas ações são baseadas em convicções, crenças e valores que implicam em desqualificação do cuidado. Essa constatação foi possível uma vez que os estudos trazem a recusa de alguns profissionais em realizar a interrupção da gestação, mesmo quando esta é advinda 
de violência sexual. Essa conduta se traduz em violência institucional, que pode acarretar problemas sexuais e reprodutivos à mulher que muitas vezes recorrem à realização do procedimento em locais ilegais e inseguros, arriscando sua vida (28). Tal recusa pode acontecer, quando o profissional considera o ato contrário aos seus valores, fazendo uso do seu direito à objeção de consciência.

A criminalização do aborto no Brasil pode resultar em violência contra a mulher, bem como negligência no atendimento, sobretudo quando este foi provocado, como uma forma de punição de graus variados ${ }^{(20,16)}$. Importante a compreensão de que se a mulher precisar de cuidados em caso de risco de vida, o enfermeiro deve atender, seguindo os preceitos éticos de respeito à vida e ao cuidado ${ }^{(15)}$. Esta questão, especialmente, reflete necessidades de reflexão e uma prática baseada em evidência e fundamentada nos princípios da humanização e acolhimento.

Uma das estratégias para minimizar os problemas relacionados ao abortamento, refere-se a ações de educação sexual nas escolas, com ênfase na importância do início do pré-natal precoce, produção de cartilhas educativas e implantação de protocolos de orientação escolar que vislumbrem a prevenção da gravidez indesejada. Também são recomendadas a notificação de dados relacionados ao aborto, por uma central pública, para estudo em cada território (municipal, estadual e nacional), para a implementação de ações de acordo com a necessidade e a realidade local ${ }^{(5)}$.

Os dados elucidaram ainda a importância de não responsabilizar apenas os profissionais que atendem as mulheres, mas envolver as instituições na perspectiva da promoção da Educação Permanente, como estratégia de sensibilização, qualificação e ressignificação de preconceitos e julgamentos. Condutas baseadas em valores e crenças pessoais podem resultar em maus-tratos, sendo necessário a promoção do acolhimento, a escuta qua-
C6

A criminalização do aborto no Brasil pode resultar em violência contra a mulher, bem como negligência no atendimento, sobretudo quando este foi provocado, como uma forma de punição de graus variados. Importante a compreensão de que se a mulher precisar de cuidados em caso de risco de vida, o enfermeiro deve atender, seguindo os preceitos éticos de respeito à vida e ao cuidado. lificada, ações de humanização para a manutenção da saúde e da vida das muIheres $^{(28)}$. Para alcançar o ideal de humanização, é necessário sensibilização dos profissionais de saúde para o exercício da atenção, do diálogo, da solidariedade, do acolhimento e da comunicação com cada usuária do serviço ${ }^{(21)}$.

Nessa perspectiva, os estudos descortinam a necessidade de que a categoria profissional deva lutar para assegurar acessibilidade à assistência qualificada, equitativa e humanizada às mulheres afetadas pelo aborto, independente de sua raça/cor, classe social ou faixa etária ${ }^{(20)}$. Em países onde essa assistência é assegurada e/ou o aborto é legalizado, outros aspectos da atenção às mulheres têm sido objeto de estudos, tais como: o direito de visualizar os produtos da concepção ${ }^{(30)}$, o acesso equitativo de mulheres marginalizadas ${ }^{(31)}$, e o aborto medicamentoso por meio da telemedicina ${ }^{(32)}$.

Um estudo realizado apenas com enfermeiros do sexo masculino relatou que em sua compreensão a mulher não é a única responsável pelo planejamento reprodutivo do casal, onde as mulheres acabam sendo as únicas vistas e culpabilizadas, mas a decisão do aborto cabe a ela por sofrer diretamente com o processo do ciclo gravídico puerperal e defendem a sua legalização como forma de prevenir a morbimortalidade ${ }^{(26)}$.

Outro aspecto muito presente nos estudos foram os sentimentos vivenciados pelas mulheres, tais como a perda, o luto, a tristeza ${ }^{(10,11,22)}$. Vivenciar o aborto, seja esse espontâneo ou provocado, pode trazer repercussões tanto para a saúde física, quanto emocional e mental dessas mulheres. Cuidar, nesse sentido, transpõe a perspectiva da competência técnica e alcança significados mais subjetivos que podem proporcionar conforto e dignidade da pessoa que é cuidada. Diante disso, para a garantia do direito à saúde, os serviços precisam ter qualidade, profissionais capacitados e implicados com as necessidades individuais e coletivas de cada usuária ${ }^{(22)}$. 
As lacunas deste estudo dizem respeito à identificação de poucos artigos de fonte primária com evidências do atendimento de enfermagem diferenciado às gestantes, durante e pós o aborto, inclusive, na atenção ao pré-natal, momento onde podem ocorrer relacionamentos terapêuticos e ações preventivas de cuidado, e aos aspectos legais que envolvem o tema e suas implicações para o cuidado, em países onde a prática envolve criminalização.
CONCLUSÃO

Nesta revisão integrativa foi identificado que a prática de enfermagem sofre influência das simbolizações dos profissionais em relação ao aborto. Os resultados mostraram que o aborto traz às muIheres diversos sentimentos e sensações, como medo, raiva, tristeza e angústia, os quais precisam ser identificados e aliviados, mas ao contrário, são potencializados e intensificados por uma assistência desumana, apática e permeada por julgamentos e críticas.

Conclui-se que a assistência da enfermagem traz implicações negativas à saúde mental da mulher que vivenciou o aborto, a exemplo do isolamento, tristeza e dor. É necessário que profissionais de Enfermagem e instituições sejam sensíveis às necessidades dessas mulheres, na perspectiva de planejar e oferecer assistência integral, centrada em suas necessidades e emoções, sem julgamentos e sem violência.

\section{Referências}

1. Ministério da Saúde (Brasil). Gestação de Alto Risco Manual Técnico. Editora MS- $5^{a}$ edição, Brasília, 2012 [acesso em 15 abril 2019].

2. Diniz D, Medeiros M, Madeiro A. Pesquisa Nacional de Aborto 2016. Ciênc. saúde coletiva [Internet]. 2017; Feb [cited 2020 May 10] ; 22( 2):653-660. 3. Anjos KF, Santos VC, Souzas R, Eugênio BG. Aborto e saúde pública no Brasil: reflexões sob a perspectiva dos direitos humanos. Saúde debate [Internet]. 2013 Sep [cited 2020 Mar 10]; 37(98):504-515.

4. COFEN. CBCENF traz reflexão sobre Saúde Coletiva e descriminalização do aborto. 2018 Nov [acesso em 20 dez 2019].

5. Ribeiro CL, Albuquerque FO, Souza AR. Internações por aborto espontâneo: um retrato de sua ocorrência em Fortaleza. Enferm. Foco 2017; 8 (1): 37-41.

6. Carvalho SM, Paes GO, Carvalho SM, Paes GO. Integrality of nursing care provided to women who have experiencing experienced an unsafe abortion. Esc. Anna Nery [Internet]. 2014 Mar [cited 2020 May 14] ; 18(1): 130-135. 7. Ministério da Saúde (Brasil). Atenção Humanizada ao Abortamento Norma Técnica. Editora MS, Brasília-DF, 2011 [acesso em 2019 ago 31].

8. Strefling ISS, Filho WDL, Demori CC et al. Cuidado de enfermagem à mulher em situação de aborto: revisão integrativa. Rev Enferm UFSM. [Internet]. 2015 Jan/Mar [acesso em 29 Ago 2019];5(1):169-177.

9. Souza MTde, Silva MD da, Carvalho R de. Revisão integrativa: o que é e como fazer. Einstein (São Paulo) [Internet]. 2010 Mar [cited 2020 May 14];8(1):102-106.

10. Melchiors L, Madi SC, Maggi A, Rosa AM et al. Análise da experiência de mulheres atendidas em um serviço de referência para vítimas de violência sexual e aborto previsto em lei, Caxias do Sul, Brasil. R e p r o d c l i m [internet]. 2015 .

11. Camarneiro Ana Paula Forte, Maciel Juraci Conceição Silveira Cardoso, Silveira Rosa Maria Garcia da. Vivências da interrupção espontânea da gravidez em primigestas no primeiro trimestre gestacional: um estudo fenomenológico. Rev. Enf. Ref. [Internet]. 2015 Jun [citado 2020 Maio 15]; serlV(5): 109-117. 12. Silva EF da et al. Atenção à mulher em processo de abortamento induzido: percepção de profissionais de enfermagem. Revista de Enfermagem da UFSM, [S.I.], v. 5, n. 3, p. 454 - 464, out. 2015. ISSN 2179-7692.

13. Strefling ISS, Lunardi Filho WD, Kerber NPC, Soares MC, Ribeiro JP. Percepções da enfermagem sobre gestão e cuidado no abortamento: estudo qualitativo. Texto contexto - enferm. [Internet]. 2015.

14. Sell SE, Evanguelia KAS, Kotzias, Velho MB, Alacoque LE, Rodriguez MJH. Motivos e significados atribuídos pelas mulheres que vivenciaram 0 aborto induzido: revisão integrativa. Revista da Escola de Enfermagem da USP [Internet]. 2015

15. Paço $S$, Deodato $S$. Objeção de consciência: reflexões para a enfermagem em Portugal. Rev. Gaúcha Enferm. [Internet]. 2015.

16. Silveira P, MCcallum C, Menezes G. Experiências de abortos provocados em clínicas privadas no Nordeste brasileiro. Cad. Saúde Pública [internet], Rio de Janeiro, v. 32, n.2, e00004815, 2016.

17. Milanez, $\mathrm{N}$ et al. Gravidez Indesejada e Tentativa de Aborto: práticas e
contextos.Sex., Salud Soc. (Rio J.) [internet], Rio de Janeiro, n. 22, p. 129-146, Apr. 2016.

18. MCcallum, $C$ et al. 0 dilema de uma prática: experiências de aborto em uma maternidade pública de Salvador, Bahia. História, Ciências, Saúde [internet] - Manguinhos, Rio de Janeiro, v.23, n.1, jan.-mar. 2016.

19. Pitilin, Érica de Brito; Banazeski, Ana Claudia; Bedin, Rafaela; Gasparin, Vanessa Aparecida. Assistência de enfermagem em situações de aborto induzido /provocado: uma revisão integrativa da literatura. Enfermería global. 2016. 20. Rodrigues WFG, Andrade DC, Dantas SA, Silva LR. Abortamento: protocolo de assistência de enfermagem: relato de experiência. Rev enferm UFPE online., Recife, 11(8):3171-5, ago., 2017.

21. Lima LM, Gonçalves SS, Rodrigues DP et al. Cuidado humanizado às muIheres em situação de abortamento: análise reflexiva. Rev enferm UFPE online., Recife, 11(12):5074-8, dec., 2017.

22. Madeiro AP, Rufino AC. Maus-tratos e discriminação na assistência ao aborto provocado: a percepção das mulheres em Teresina, Piauí, Brasil. Ciênc. saúde coletiva [internet], Rio de Janeiro, v. 22, n. 8, p. 2771-2780, Ago. 2017. 23. Santos DLA, Brito RS. Sentimentos de mulheres diante da concretização do aborto provocado. Rev enferm UERJ[internet], Rio de Janeiro, 2016.

24. Fernandes IB, Xavier RB, São Bento PAS, Rodrigues A. Nas vias de interromper ou não a gestação: vivências de gestantes de fetos com anencefalia. Ciência \& Saúde Coletiva, 25(2):429-438, 2020

25. Martins EF, Almeida PFB, Paixão CO, Bicalho PG, Errico LSP. Causas múltiplas de mortalidade materna relacionada ao aborto no Estado de Minas Gerais, Brasil, 2000-2011. Cad. Saúde Pública [Internet]. 2017.

26. Ayres R, Martins AC, Xavier RB, São Bento PAS, Silva JN. A contextualização do aborto sob a ótica do enfermeiro. Revista Nursing, 2018; 21 (244):23342337.

27. Patrício SS, Gregório VRP, Pereira SM, Costa R. Malformação fetal com possibilidade de interrupção legal: dilemas maternos. Rev. Bras. Enferm. [Internet]. 2019.

28. Moreira GAR, Vieira LJES, Cavalcanti LF, Silva RM, Feitoza AR. Manifestações de violência institucional no contexto da atenção em saúde às mulheres em situação de violência sexual. Saude soc. [Internet]. 2020.

29. Santos CS, Silveira LMC. Percepções de Mulheres que Vivenciaram o Aborto sobre Autonomia do Corpo Feminino. Psicol. cienc. prof.[internet], Brasília, v. 37, n. 2, p. 304-317, Jun 2017.

30. Hann LR, Becker A. The option to look: patient-centred pregnancy tissue viewing at independent abortion clinics in the United States, Sexual and Reproductive Health Matters. [Internet]. 2020.

31. Prodan-Bhalla N, Browne AJ. Exploring women's health care experiences through an equity lens: Findings from a community clinic serving marginalised women. J Clin Nurs. [Internet]. 2019.

32. Grindlay, K; Grossman, D. Telemedicine provision of medical abortion in Alaska: Through the provider's lens. Journal of Telemedicine and Telecare. [Internet]. 2017. 